\title{
Differential proteomic profiling to study the mechanism of cardiac pharmacological preconditioning by resveratrol
}

\author{
Karel Bezstarosti b, Samarjit Das a, Jos. M. J. Lamers b, Dipak K. Das a \\ a Cardiovascular Research Center, University of Connecticut School of Medicine, Farming CT, USA \\ ${ }^{b}$ Department of Biochemistry, Cardiovascular Research School COEUR, Erasmus Medical Center,
} Rotterdam, The Netherlands

Received: September 25, 2006; Accepted: November 1, 2006

\begin{abstract}
Recent studies demonstrated that resveratrol, a grape-derived poly phenolic phytoalexin, provides pharmacological preconditioning of the heart through a NO-dependent mechanism. To further explore the molecular mechanisms involved in resveratrol-mediated cardioprotection, we monitored the effects of resveratrol treatment after ischemia-reperfusion on the protein profile by implementation of proteomic analysis. Two groups of rats were studied; one group of animals was fed resveratrol for 7 days, while the other group was given vehicie only. The rats were sacrificed for the isolated working heart preparation and for isolation of cytoplasmic fraction f $\mathrm{m}$ left ventricle homogenates to carry out the proteomic as well as immunoblot at baseline and at the end of $30 \mathrm{~min}$ is hemia/2- periusion. The results demonstrate significant cardioprotection with resveratrol evidenced by improved entricular ecovery and reduced infarct size and cardiomyocyte apoptosis. The left ventricular cytoplasmic fraction were separated by two-dimensional electrophoresis (2-DE). Differentially regulated proteins were detected with quantitat ve compute analysis the Coomassie blue stained 2-DE images and identified by MALDI-TOF (MS) and nanoLC-ESI-Q-TOF mass spectrometry (MS/MS). Five redox-regulated and preconditioning-related proteins were identifie that were all upregulated by resveratrol: MAPKK, two different $\alpha \mathrm{B}$-crystallin species, HSP 27 and PE binding protein. Another HSP27 species and aldose reductase were downregulated and peroxiredoxin-2 remained constant. The resurts of the immunob analysis of phosphorylated MAPKK, -HSP27 and - $\alpha \mathrm{B}$-crystallin and PE binding protein were consistent with the proteomic findings, but not with peroxiredoxin- 2 . The proteomic analysis showed also do wnregulation of some protens in the mitochondrial respiratory chain and matrix and the myofilament regulating prote MLC kinase-2. The resuls of the present study demonstrate that proteomic profiling enables the identification of resv trol in fuced preconditioning-associated proteins which reflects not only changes in their expression level but also iso fors, post-trans lational modifications and regulating binding or activating partner proteins.
\end{abstract}

Keywords: ischemia/reperfusion • heart • resveratrol • proteomics $\bullet \alpha$ B-crystallin $\bullet$ hsp27 • phosphatidylethanolamine binding protein

\section{Introduction}

A growing body of evidence exists in the literature supporting cardioprotective role of resvera-

\footnotetext{
* Correspondence to: Dipak K. DAS, Ph.D., FAHA

Cardiovascular Research Center, University of Connecticut, School of Medicine, Farmington, CT 06030-1110, USA.

Tel.: (860) 679-3687; Fax: (860) 679-4606

E-mail: DDAS@NEURON.UCHC.EDU
}

trol, a grape and wine derived polyphenolic compound. Resveratrol reduces myocardial ischemic reperfusion injury by rendering the heart resistant against the injury through pharmacological preconditioning [1-5]. Striking similarities between the mechanisms of ischemic preconditioning (IPC) and resveratrol mediated preconditioning 


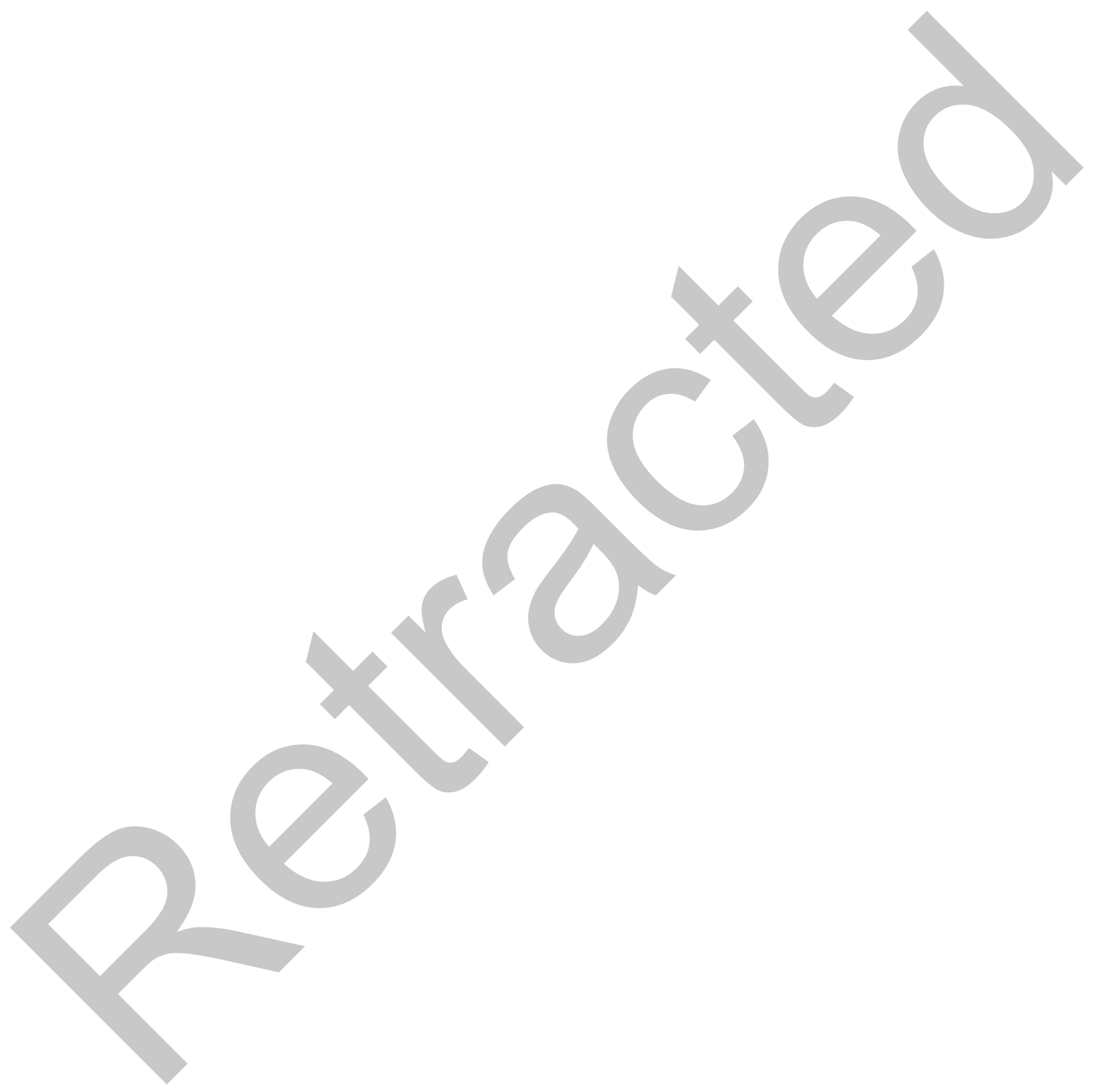


exists. For example, adenosine and $\mathrm{K}^{+}$ATP channels are involved in the preconditioning process in either cases, and both use nitric oxide (NO) as primary target through the induction of iNOS and eNOS [6-8]. Similar to classical IPC, resveratrol preconditions the heart through adenosine $\mathrm{A}_{1}$ and $\mathrm{A}_{3}$ receptors by triggering a survival signal through the activation of PI-3-kinase-Akt pathways [9], which then leads to the activation of cell survival protein Bcl-2 [10].

It is becoming increasingly clear that pharmacological PC by resveratrol involves complex molecular signaling mechanisms involving many proteins in the crossroads of death and survival pathways. Therefore, the identification of the (post-translationally modified) target proteins that participate in resveratrol signaling should provide important insights into the cellular and molecular basis of the protective action of resveratrol.

The novel developments in the proteomic technology allows us for the first time to examine global alterations of protein expression and, when present, their post-translational modifications in the resveratrol-treated ischemia reper fused heart and, thereby, it can potentially provide new insights into the cellular mechanisms involved in the signaling leading to cell survival [11-14]. Proteomics typically uses two-dimen sional gel electrophoresi (2-DE) coupled with mass spectrometry (MS) to identify differentially displayed proteins which are obtained by matching gel images obtaine fom baseline, ischemia-reperfused without and with resveratrol treatment. The present proteomic study identifies a number of post-translationally modified) protein that become upregulated in the resveratrol treated ischemia-reperfused hearts and of which only a part, such as mitogen-activated protein kinase kinase (MAPKK) and $\mathrm{phosphorylation} \mathrm{of} \alpha \mathrm{B}$-crystallin and HSP2 7 were known to sit at the crossroad of death and survival signaling pathways. The resveratrol-induced upregulation of these preconditioning associated proteins was substantiated to a part by subsequent immunoblot analysis. The proteomic findings demonstrate that this novel approach provides not only direct information on protein expression level but also post-translational modifications and alteration of regulating binding or activity partners.

\section{Material and methods}

\section{Animals}

All animals used in this study received humane care in compliance with the principles of the laboratory animal care formulated by the National Society for Medical Research and Guide for the Care and Use of Laboratory Animals prepared by the National Academy of Sciences and published by the Nation Institutes of Health (Publication Num Ner NIH 85-23 revised 1985). Sprague Dawley male rats weighing between 250-300 gm were fed ad libitum regular ta chow with free access to ater until the start of the experimental procedure. The rats were randomly assigned to one of the twe groups. Fed re eratrol $[2.5$ $\mathrm{mg} / \mathrm{kg}$ dissolved in $0.1 \mathrm{mi}$ of $50 \%$ alcohol diluted to $0.5 \mathrm{ml}$ with water] Sigma Chemical Co, St. Louis, Mo] or vehicle $\lceil 0.1 \mathrm{ml} 50 \%$ alcohol diluted to $0.5 \mathrm{ml}$ with wate1] through gavaging foy a period of 7 days.

\section{Isolat working heart preparation}

Rats were anesthetized with sodium pentobarbital $80 \mathrm{mg} / \mathrm{kg}$, i.p.), (Abbott Laboratories, North Chicago, L, USA) and anticoagulant with heparin sodiv (500 IU/kg. i.v.) (Elkins-Sinn Inc., Cherry Hill. NJ, USA). After ensuring sufficient depth of anesthesia thoracotomy was performed, hearts were perfused in the retrograde Langendorff mode at $37^{\circ} \mathrm{C}$ at a constant perfusion pressure of $100 \mathrm{~cm}$ of water $(10 \mathrm{kPa})$ for a 5 min washout period. The perfusion buffer used in this study consisted of a modified Krebs-Henseleit bicarbonate buffer (KHB) (in mM: sodium chloride 118 , potassium chloride 4.7 , calcium chloride 1.7 , sodium bicarbonate 25 , potassium biphosphate 0.36 , magnesium sulfate 1.2 , and glucose 10). The Langendorff preparation was switched to the working mode following the washout period as previously described [15].

At the end of $10 \mathrm{~min}$, after the attainment of steady state cardiac function, baseline functional parameters were recorded. The hearts were then subjected to global ischemia for $30 \mathrm{~min}$ and then $2 \mathrm{~h}$ of reperfusion. The first $10 \mathrm{~min}$ of reperfusion was in the retrograde mode to allow for post ischemic stabilization and there after, in the antegrade working mode to allow for assessment of functional parameters, which were recorded at 10-, 30-, 60- and 120- min reperfusion. 


\section{Cardiac function assessment}

Aortic pressure was measured using a Gould P23XL pressure transducer (Gould Instrument Systems Inc., Valley View, OH, USA) connected to a side arm of the aortic cannula, the signal was amplified using a Gould 6600 series signal conditioner and monitored on a CORDAT II real-time data acquisition and analysis system (Triton Technologies, San Diego, CA, USA). Heart Rate (HR), Left Ventricular Developed Pressure (LVDP) (defined as the difference of the maximum systolic and diastolic aortic pressures), and the first derivative of developed pressure $(\mathrm{dP} / \mathrm{dT})$ were all derived or calculated from the continuously obtained pressure signal. Aortic flow (AF) was measured using a calibrated flow-meter (Gilmont Instrument Inc., Barrington, IL, USA) and coronary flow $(\mathrm{CF})$ was measured by timed collection of the coronary effluent dripping from the heart [15].

\section{Infarct size estimation}

At the end of reperfusion, the left ventricle was cut into transverse slices [16]. The slices were incubated in triphenyl tetrazolium solution in phosphate bufer $\left[\mathrm{Na}_{2} \mathrm{HPO}_{4} 88 \mathrm{mM}, \mathrm{NaH}_{2} \mathrm{PO}_{4} 1.8 \mathrm{mM}\right]$ for $20 \mathrm{~min}$ a $37^{\circ} \mathrm{C}$. This procedure distinguishes necrotic tissue from viable myocardium. The slices were stored for $48 \mathrm{~h}$ in $10 \%$ buffered formalin. The heart sl ces were photographed and the weights of the slices were monitored. Digital images of the slices were magnified, and the area of necros is each slice was quantified by computerized planimetry. The risk and infarct volumes in $\mathrm{cm}^{3}$ of each slice were then calculated on the basis of slice weight to remove the introduction of any errors cue to non-unifornity of heart slice thickness. The risk volumes and infaret volumes of each slice were summed to obtain the risk and infarct volumes $i$ the whole heart. Infarct size was aken to be the percent infarct volume of risk volume for any one heart.

\section{TUN EL assay for assessment of apopto tic cell death}

Immunohistochemical detection of apoptotic cells was carried out using TUNEL [17]. The sections were incubated again with mouse monoclonal antibody recognizing cardiac $\alpha$-myosin heavy chain to specifically recognize apoptotic cardiomyocytes. The fluorescence staining was viewed with a confocal laser microscope. The number of apoptotic cells was counted and expressed as a percent of total myocytes population.

\section{2-DE separation of cytoplasmic proteins}

Small pieces $(0.1-0.2 \mathrm{~g})$ of the left ventricle of the excised hearts from control, ischemia-reperfused with and without resveratrol treatment groups were homoenized in $100 \mu$ l of sample buffer $(15 \mathrm{mM}$ Tris-HCI mM EGTA, protease inhibitor cocktai Complete TN (Roche, Mannheim, Germany) with a microdismembrator (Braun, Melsungen, Germany) at liquid nitro gen temperature. After thewing at $0-4^{\circ} \mathrm{C}$, protein concentration was measured with the $D C$ protein assay (Bio Rad, Hercules CA). Hom genates were stored at $-80^{\circ} \mathrm{C}$. Sub-fractionation of the homogenates $(600 \mu \mathrm{g}$ of protein) was achieved as described previously [12] by adding $5 \%$ Triton $X-100(\mathrm{v} / \mathrm{v} 1: 4)$, incubating for 1 $\mathrm{h}$ at $4^{\circ} \mathrm{C}$ and subsequently oentifuging for $15 \mathrm{~min}$ at $13,400 \times \mathrm{g}$. The firs supernatant (cytoplasmic fraction) was collected and the pellet (myofilament fraction) Was resuspend in $10 \mu 11 \%$ triton $\mathrm{X}-100$ and entrifuged. The second supernatant was added to the fi st, completing the cytoplasmic fraction. Only this top lasmic fraction was analyzed by 2-DE combined with ic ntification of differentially displayed by MS and im nunoblotting.

Is oelectric focusing (IEF) was performed using IPG strips (Amersham Biosciences, Buckinghamshire, UK) with a nonlinear $\mathrm{pH}$ range of 3-10. Rehydration buffer (350 $\mu \mathrm{l}: 7.8 \mathrm{M}$ urea, 2.2 M thiourea, 0.28\% CHAPS, $0.9 \%$ Triton X-100, $11.1 \%$ isopropanol, $13.9 \%$ water saturated isobutanol, $5.6 \%$ glycerol, protease inhibitor cocktail Complete TM (Roche), a few grains of bromophenol blue, $69 \mathrm{mM}$ DTT, $0.6 \% \mathrm{v} / \mathrm{v}$ biolytes) was added to both subfractions. The homogenates were applied to the IPG strips and rehydration was performed overnight at room temperature in a reswelling tray. Next, the strips were focused in a Protein IEF Cell (Bio-Rad) according to the following protocol: $250 \mathrm{~V}$; $1 \mathrm{~h}, 500 \mathrm{~V}$; 1 hand $8000 \mathrm{~V}$ until $60 \mathrm{kVCh}$ was reached. Next the IPG strips were equilibrated in the SDS-equilibration buffer $(50 \mathrm{mM}$ tris- $\mathrm{HCl} \mathrm{pH} 8.8,6 \mathrm{M}$ urea, $30 \%$ glycerol, $2 \%$ SDS) with the addition of DTT (10 $\mathrm{mg} / \mathrm{ml}$ ) for $15 \mathrm{~min}, 9$ followed by $15 \mathrm{~min}$ in the same buffer with the addition of iodoacetamide $(25 \mathrm{mg} / \mathrm{ml})$. SDSPAGE was performed $(180 \mathrm{~mm} \times 180 \mathrm{~mm} \times 1 \mathrm{~mm}$ polyacrylamide gel $(12 \%)$ using the Protean II XL Cell System (Bio Rad). The IPG strips were sealed in place 

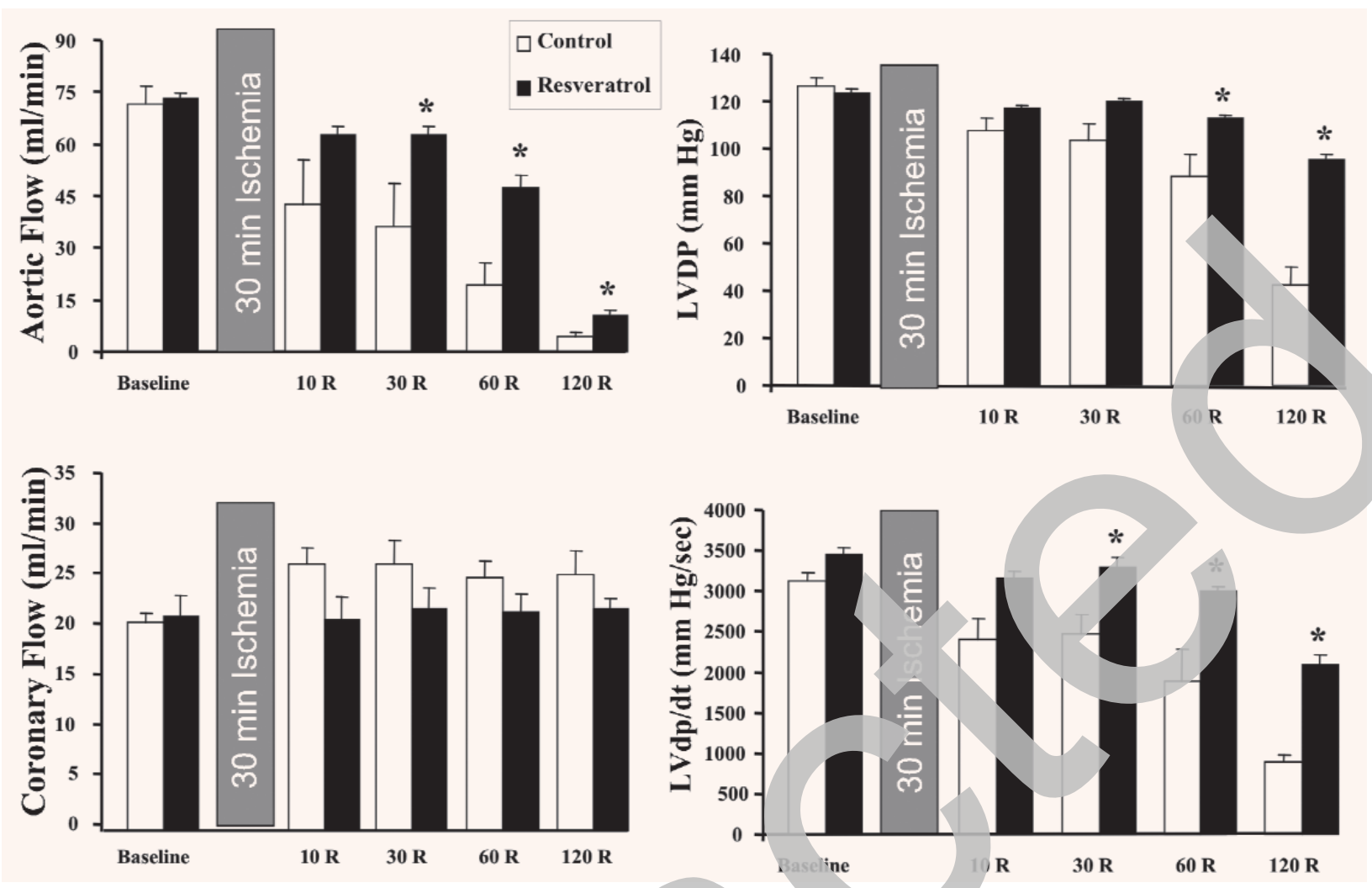

Fig. 1 Effects of resveratrol on the recovery of p -ischemic feft ventricular function. Rats were fed resveratrol ( $2.5 \mathrm{mg} / \mathrm{kg}$ for 7 days) by gavaging. The control ts were given 50\% ethyl alcohol by gavaging, and kept under identical conditions. At the end of 7 days, the ra were acrificed, the hearts excised for isolated working heart preparation. LVDP: left ventricular develo pressure; LV dp/dt: naximum first derivatives of developed pressure. Results are expressed as the mean of \pm . . M. of six an imals in ach group. ${ }^{*} p<0.05$, resveratrol versus control.

with a $1 \%$ agarose solution, together with protein mass standard. The 2-DE was carried out at $25 \mathrm{~V} / \mathrm{gel}$ for 1 hand then $24 \mathrm{~mA} / \mathrm{gel}$, and was stopped when the bromophenol blue front reached the bottom of the glass plate (total cuation $4,6 \mathrm{~h}$ ) Temperature was kept constant at $25^{\circ}$ by thermost t-controlled circulating water

After the 2-DE separation, he gels were fixed overnight in $40 \%$ ethanol and $10 \%$ acetic acid. Next, the gels were washed in distilled water. CBB staining (Coomassie Brilliant Biue Staining) was performed for a min mal of $24 \mathrm{~h}$ in a $34 \%$ methanol, $17 \%\left(\mathrm{NH}_{4}\right)_{2} \mathrm{SO}$, $2 \% \mathrm{H}_{3} \mathrm{PO}_{4}$, and $0.066 \%$ CBB G-250 solution.

The CBB stained gels were scanned with a GS-800 calibrated densitometer (Bio Rad, HERCULES, CA, USA) and imaged and analyzed with the PDQUEST software (Bio Rad, HERCULES, CA, USA). In PDQUEST, the images of the eight groups were compared. Normalization of the gels was based on the total staining density of the image.

\section{Identification of differentially displayed proteins}

Significantly up- and downregulated spots were excised in duplicate from the CBB stained gels and identified by nanoLCESI-Q-TOF-MS/MS as described previously [12]. Briefly, the gel plugs were destained using a destaining solution $\left(1 \mathrm{~g}\left(\mathrm{NH}_{4}\right) \mathrm{HCO}_{3}, 175 \mathrm{ml}\right.$ distilled water, $75 \mathrm{ml}$ acetonitrile) until colorless. Subsequently, the gel-plugs were dried using a centrifugal evaporator. The gel-plugs were incubated overnight with trypsin (ultra sequencing grade, Promega, Madison, WI) at room temperature. Trypsin digestion was stopped by adding a solution of $1: 2$ CAN and $0.1 \%$ TCA to the gel plugs. The sample solution was co-crystallized with matrix (6 mg a-cyano cinnamics acid, $1 \mathrm{ml}$ ACNM) on to a 400 $\mu \mathrm{m}$ anchor chip plate and air-dried before loading into the MALDITOF-MS (Bruker Daltonics, Billerica, MA). In almost all spots identification was additionally 

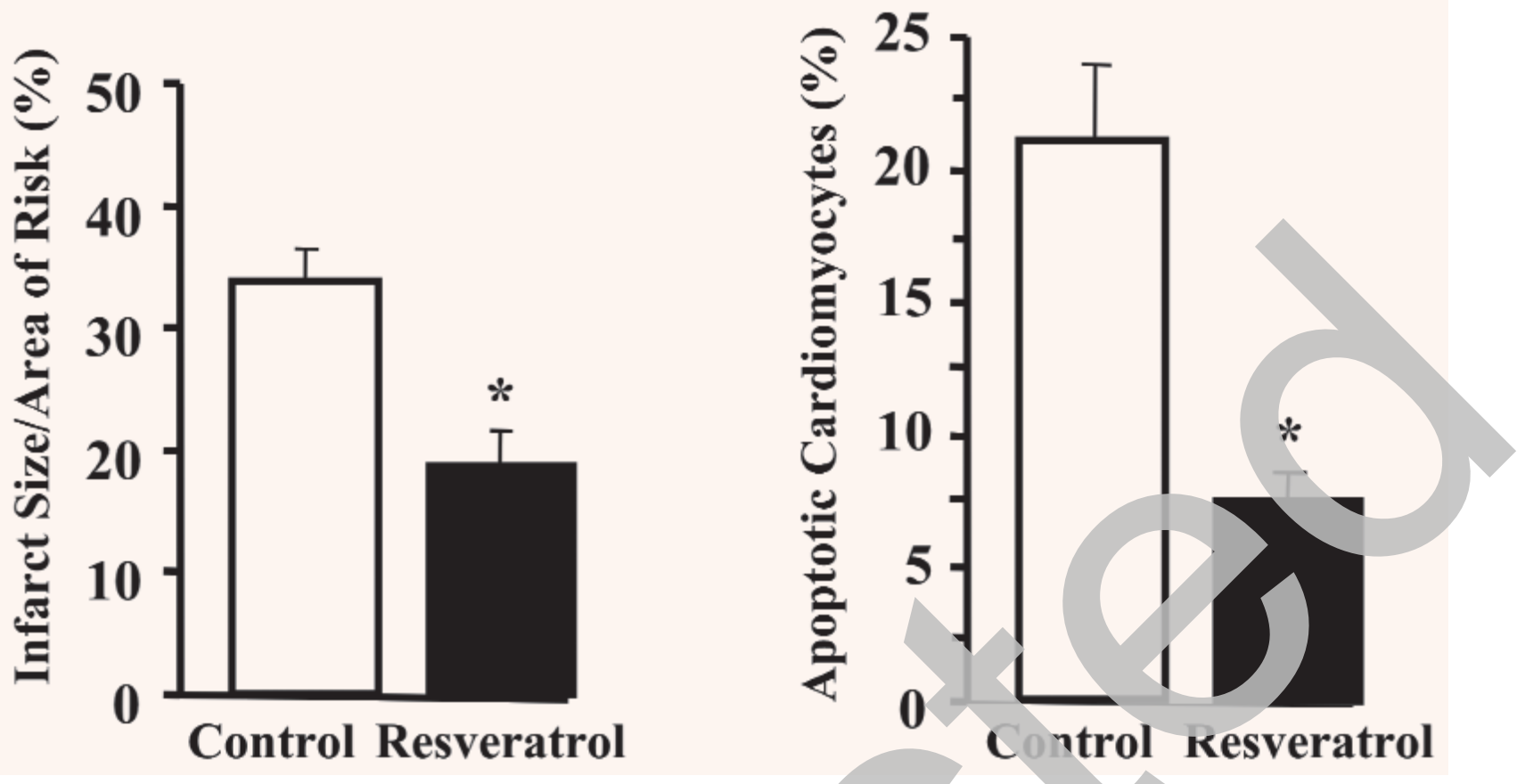

Fig. 2 Effects of resveratrol on myocardial infarct size and cardio myocyte apoptosis. The isolated hearts from control $(\mathrm{n}=6)$ and resveratrol-fed $(\mathrm{n}=6)$ rats were subjected to $30 \mathrm{~min}$ of glob al ischemia followe $\mathrm{d}$ by $2 \mathrm{~h}$ of reperfusion in a working mode. Infarct size was measured by the TTC dye method while apotosis was measured by TUNEL method in conjunction with antibody against $\alpha$-myosin heavy chain. $\mathrm{R}$ expre

confirmed by nanoLC-ESI-QTOF MS/MS (Water Milford, MA), which generated peptide sequence i addition to peptide mass inf mation (see eg. Fig. 4). Peptide masses and, if necessary sequences, were used to search the $\mathrm{MASCO}^{-}$protein database (http://www.matrixscience.com). The Swiss-P ot database (http://www expasy org) was searched to obtain further struct rand and inctional cetails on the proteins that were identified

\section{amunob} analys

For the confirmative immunoanalysis of differentially dis played preconditioning-associated proteins small tissue pieces from the left ventricles from the hearts were homogenized in a buffer containing $25 \mathrm{mM}$ Tris$\mathrm{HCl}, 25 \mathrm{~m} \mathrm{NaCl}, 1 \mathrm{mM}$ orthovanadate, $10 \mathrm{mM} \mathrm{NaF}$, $10 \mathrm{mM}$ pyrophosphate, $10 \mathrm{mM}$ okadaic acid, $0.5 \mathrm{mM}$ EDTA and $1 \mathrm{mM}$ PMSF (Sato et al., 2000). $100 \mu \mathrm{g}$ of protein of each heart homogenate was incubated with 1 $\mu \mathrm{g}$ of antibody against the HSP27, $\alpha \mathrm{B}-$ Crystallin, peroxiredoxin 2, MAP kinase kinase and PE binding protein (Santa Cruz Biotechnology, Inc., Santa Cruz, CA) for $1 \mathrm{~h}$ at $+{ }^{\circ} \mathrm{C}$. The immune complexes were precipitated ith protein A Sepharose, immunoprecipitates separated by SDS-PAGE and immobilized on polyvinylidene difluoride membrane. The membrane was stripped and reblotted with specific antibodies against glucose-6-phosphate dehydrogenase, which served as loading control. The resulting blots were digitized and subjected to densitometric scanning using a standard NIH image program.

\section{Statistical analysis}

The differential analysis software PDQUEST (MannWhitney) was primarily used for the identification of up- and down- regulated spots comparing the duplicate left ventricular samples obtained from each animal group. As to the statistical analysis of the heart function and images of the immunoblots the statistical software program SPSS (version 10.1 for windows, Microsoft) was used to reevaluate the Mann-Whitney statistics and calculate the exact $p$-values. Data are presented as means \pm SEM. A p-value of $<0.05$ was considered statistically significant. 
Table 1 List of the identified differentially expressed proteins by comparing the 2-DE images of control and ischemiareperfused hearts and ischemiareperfused hearts from resveratrol treated hearts

\begin{tabular}{|c|c|c|c|c|c|c|c|c|c|c|}
\hline $\begin{array}{l}\text { PDQUEST } \\
\text { SSP nr }\end{array}$ & $\begin{array}{c}\text { Control } \\
\text { ppm }^{b}\end{array}$ & $\begin{array}{c}\text { IR } \\
\text { ppm }^{b}\end{array}$ & $\begin{array}{c}\mathrm{IR}+\mathrm{R} \\
\mathbf{p p m}^{\mathrm{b}}\end{array}$ & $\begin{array}{c}\text { Effect of } \\
\text { resveratrole }\end{array}$ & Protein identification & $\begin{array}{l}\text { Mowse } \\
\text { score }^{\mathrm{a}}\end{array}$ & \multicolumn{2}{|c|}{$\begin{array}{c}\mathbf{M}_{\mathrm{w}} \quad \mathrm{pI}^{\mathrm{c}} \\
\text { Theortical }\end{array}$} & \multirow[t]{2}{*}{$\begin{array}{c}\% \\
\text { sequence } \\
\text { coverage }\end{array}$} & \multirow[t]{2}{*}{$\begin{array}{c}\text { Protein } \\
\text { Accession nr }\end{array}$} \\
\hline \multicolumn{9}{|c|}{ Preconditioning (redox) regulated stressproteins } & & \\
\hline 6401 & 565 & 78 & 475 & $\uparrow \uparrow$ & $\begin{array}{l}\text { Mitogen-activated protein } \\
\text { kinase kinase }\end{array}$ & 77 & 44539 & 6.62 & 3 & gi 1096928 \\
\hline 23 & 387 & 278 & 309 & $=$ & Peroxiredoxin 2 (Q6PDV3) & 159 & 21995 & 5.34 & 14 & 100 \\
\hline 2103 & 551 & 97 & 310 & $\uparrow \uparrow$ & HSP27 (JN0924) & 239 & 22865 & $6.12^{\mathrm{c}}$ & 24 & gi|204665 \\
\hline 3101 & 425 & 308 & 198 & $\downarrow$ & HSP27 (JN0924) & 299 & 22865 & $6.12^{\mathrm{c}}$ & 24 & gi|204665 \\
\hline 6001 & 187 & 188 & 756 & $\uparrow \uparrow$ & $\alpha \mathrm{B}$-crystallin (Q80XO3) & 144 & 20155 & $6.84^{\mathrm{c}}$ & 17 & gi| 57580 \\
\hline 7009 & 10295 & 6446 & 10958 & $\uparrow$ & $\alpha \mathrm{B}$-crystallin (Q80XO3) & 157 & 20155 & & & \\
\hline 1005 & 1114 & 1516 & 3348 & $\uparrow \uparrow$ & PE binding protein (PEBP-RAT) & 396 & 20771 & 48 & 8 & gi|8393910 \\
\hline 5201 & 565 & 595 & 288 & $\downarrow$ & Aldose reductase (ALDR-RAT) & 247 & 36099 & .28 & 11 & gi|6978491 \\
\hline \multicolumn{11}{|c|}{ Mitochondrial respiratory chain } \\
\hline 4603 & 1228 & 1185 & 334 & $\downarrow \downarrow$ & $\begin{array}{l}\text { Flavoprot subunit succ dehydr } \\
\text { (Q92OL2) }\end{array}$ & 30 & & & & gi|18426858 \\
\hline 4404 & 2040 & 1300 & 1190 & $=$ & $\begin{array}{l}\text { Pyruvate dehyd á chain } 1 \text { prec } \\
\text { (DERTP1) }\end{array}$ & 7 & & 0 & 30 & gi $\mid 57657$ \\
\hline 4306 & 315 & 263 & 143 & $\downarrow$ & $\begin{array}{l}\text { Acyl-Coa dehyd short. } \\
\text { (ACDS-RAT) }\end{array}$ & 430 & 45022 & 35 & 19 & gi|1168286 \\
\hline 5203 & 354 & 145 & 139 & $=$ & $\begin{array}{c}\text { Glycerol-3P dehydroge } \\
\text { (GPDARAT) }\end{array}$ & 422 & 37869 & 6.34 & 20 & gi|57527919 \\
\hline \multicolumn{11}{|c|}{ Cytoskeletal and myofilament regulating proteins } \\
\hline \multirow{3}{*}{$2105 f$} & 954 & 1483 & 783 & $\downarrow$ & $\begin{array}{l}\text { MI }-2 \text { cardia } \\
\text { (MLV-PAT) }\end{array}$ & 68 & 18737 & 4.9 & 10 & gi|56683 \\
\hline & 175 & 188 & 110 & 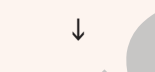 & $\begin{array}{l}\text { in sm } 1 \mathrm{mu} \\
(\mathrm{A} C \mathrm{ASM})\end{array}$ & 253 & 42381 & 5.23 & 13 & gi|4501883 \\
\hline & & & & & $\begin{array}{l}\text { asome activator } r \text { ? } 28 \beta \\
\quad(\mathrm{I} 67638)\end{array}$ & 151 & 27068 & 5.52 & 8 & gi|1008932 \\
\hline \multicolumn{11}{|c|}{ Miscellaneous } \\
\hline 7001 & 1050 & 1867 & & & $\begin{array}{l}\text { lobin (hypothetical prot.) } \\
\text { (Q9OZ76) }\end{array}$ & 110 & 17203 & $7.83^{\mathrm{c}}$ & 9 & gi|11024650 \\
\hline 6501 & 95 & & & & $\begin{array}{l}\text { Adenylcyclase assoc. prot } \\
\text { CAP2 (JC4386) }\end{array}$ & 67 & 53164 & 6.69 & 4 & gi|16758742 \\
\hline 6116 & 482 & & & & $\begin{array}{l}\text { 2-enoyl-CoA hydratase chain B } \\
\text { (1DUBB) }\end{array}$ & 203 & 28427 & 6.41 & 9 & gi|3212683 \\
\hline & & & & & $\begin{array}{l}\text { 3-methyl-2-oxobutanoate dihy- } \\
\text { dro (DERTXA) }\end{array}$ & 324 & 50418 & $7.68^{c}$ & 13 & gi|129032 \\
\hline $403 t$ & 20 & 127 & 200 & $\uparrow$ & $\begin{array}{c}\text { 3-methyl-2-oxobutanoate dihy- } \\
\text { dro (DERTXA) }\end{array}$ & 221 & 50418 & $7.68^{c}$ & 7 & gi|129032 \\
\hline & & & & & $\begin{array}{l}\text { Adenosine kinase } \\
\text { (ADK-RAT) }\end{array}$ & 90 & 40494 & 6.11 & 6 & gi|1373230 \\
\hline
\end{tabular}

Identifiction was achieved by nanoLC-ESI-Q-TOF-MSMS in combination with Mascot search engine (www.matrixsciences.com). The search vas performed in the NCBI database (species: rattus). The relative protein intensity on the 2-DE image is expressed as ppm. IR is an bbreviation for ischemia-reperfusion and $\mathrm{R}$ stands for resveratrol.

a Mascot Mowse score of 30 was the threshold for $\mathrm{p}<0.05$.

$\mathrm{b}$ The ppm's represent the average of values from 2 rats in each group

c Observed $\mathrm{pI}$ appears to be clearly different from the theoretical $(\Delta \mathrm{pI}>0.5)$

$\mathrm{d}$ In this spot two different proteins were identified, which causes that the ppm values make no sense

e $\uparrow$ and $\downarrow$ means respectively up- and downregulated comparing IR versus IR plus R(esveratrol). = means not altered.

${ }^{\mathrm{f}}$ According to the MS/MS analysis these spot contains two different proteins which means that their individual concentrations in ppm can not be assessed. 


\section{Results}

\section{Cardioprotection with resveratrol}

Resveratrol improved post-ischemic ventricular function as evidenced by improved recovery of coronary flow, left ventricular developed pressure and maximum first derivative of developed pressure (Fig. 1). There were no changes in coronary flow and heart rate (data not shown). Myocardial infarct size was significantly reduced after resveratrol feeding (Fig. 2). In parallel, cardiomyocyte apoptosis was also significantly lowered in resveratrol treated group.

\section{Analysis of the 2-DE gel images}

A representative PD-QUEST generated virtual image of the cytoplasmic protein separation by 2DE is illustrated in Fig. 3 and shows all spots that could be matched and that were present in at least two or more of the gels. Several spots were clustered and undistinguishable, and therefore, not included in the analysis. On the average a, total of about 360 protein spots could consistently be matched. Differential an alysis by the PD-QUEST software of the two 2-DE i nes of ischemia-reperfused versus resverntrol-treated ischemia-reperfused hearts in the backgro nd of 2-DI images of the baseline perf sed hearts, gave a large number (about 30) of protein spots, some or wich were up- or down regulated due to ischemia-reper usion and/or resveratrol treatment. Difierential expression was only based on comparing the average spot intensities in ppm of 2 hearts of each the 2 animal groups.

The differentially expressed proteins are indicated with their notation by SSP number as given in the P Q UEST program in Ig. 3 and the ones (about 20) hat could be identified by tancen MS are described in more detai in Table 1. As shown in Figure 3, the molecular weight ( $\mathrm{M}_{\text {at }} \mathrm{V}$-axis) and $\mathrm{pI}(\mathrm{X}$-axis) range the $2-D$ E separation were from 120 to $10 \mathrm{kDa}$ and 4 respectively. Interestingly, for several of the differentially displayed proteins, such as the HSP27s, one of the $\alpha B$-crystallin species and short chainacyl-CoA cehydrogenase, the apparent Mwt and/or pI on 2-DE differed clearly from the theoretical value. This would tend to suggest that the proteins were subjected to post-translational modification.

Of particular interest is the increased expression of MAPKK, both $\alpha \mathrm{B}$-crystallin species, one of the
HSP 27 species and PE binding protein (Table 1), which are known as redox-regulated proteins [18, $19]$ and have also been demonstrated to play a role in preconditioning $1[20,21]$. However as appears from this first differential proteomic display analysis of the resveratrol preconditioned hearts, this technology extends the protein expression profile by real separation of unmodified as well as (novel) post-translational forms of proteins associated w ith cardiac protection. Fig. 4 illustrates examples of $t$ th real individual 2-DE gel images with spots contain ing these redox-regulated and preconditioningrelated proteins. In almost all spots the identifica tion was definitely confirned by tandem MiS/MIS, which generated peptice sequence in ddition to peptide mass information of which one example MS/MS spectrum, is shown in Fig. 5

The salient features of the present proteomic analysis include also downregulation of some proteins in ine mitochondrial respiratory chain and matrix and interestingly the inyofilament regulating cardiac MLC-kinase-2 (Table 1). In the latter respect should be referred to the detailed proteomic lysis on pharmacological preconditioning by adenosine though in isolated rabbit cardiomyocytes posed to simulated ischemia-reperfusion. Our present observation of downregulation of cardiac MLCK -2 by resveratrol after ischemia-reperfusion in the cytoplasmic fraction may, therefore, be of particular interest [22].

\section{Immunoblot analysis}

In order to substantiate the proteomic findings with the conventional type of analysis, we performed immunoblotting on 1-DE gels of (phospho) proteins corresponding to the differentially expressed preconditioning-related proteins from all hearts of the 2 animal groups. The results are shown in Fig. 6, which shows the validation of the proteomic findings by Western blot analysis. As expected, resveratrol maintained the higher levels of the phosphorylated forms of MAPKK, $\alpha B-$ crystallin and HSP 27 after ischemia/reperfusion. Likewise, a marked increase of expression of PE binding protein was observed. However interestingly, peroxiredoxin-2 showed also increased expression, which is at variance with the outcome in the proteomic analysis. 
Fig. 3 Representative virtual image of a 2-DE gel resembling the cytoplasmic subproteome of rat left ventricle. Differentially expressed protein in the three different cytoplasmic fraction are each of them indicated by their PDQUEST SSP numbers. More information on the numbered spots is given in Table 1 . The outlined section of the image is meant to show the part of which the individual ones are given in Fig. 4.

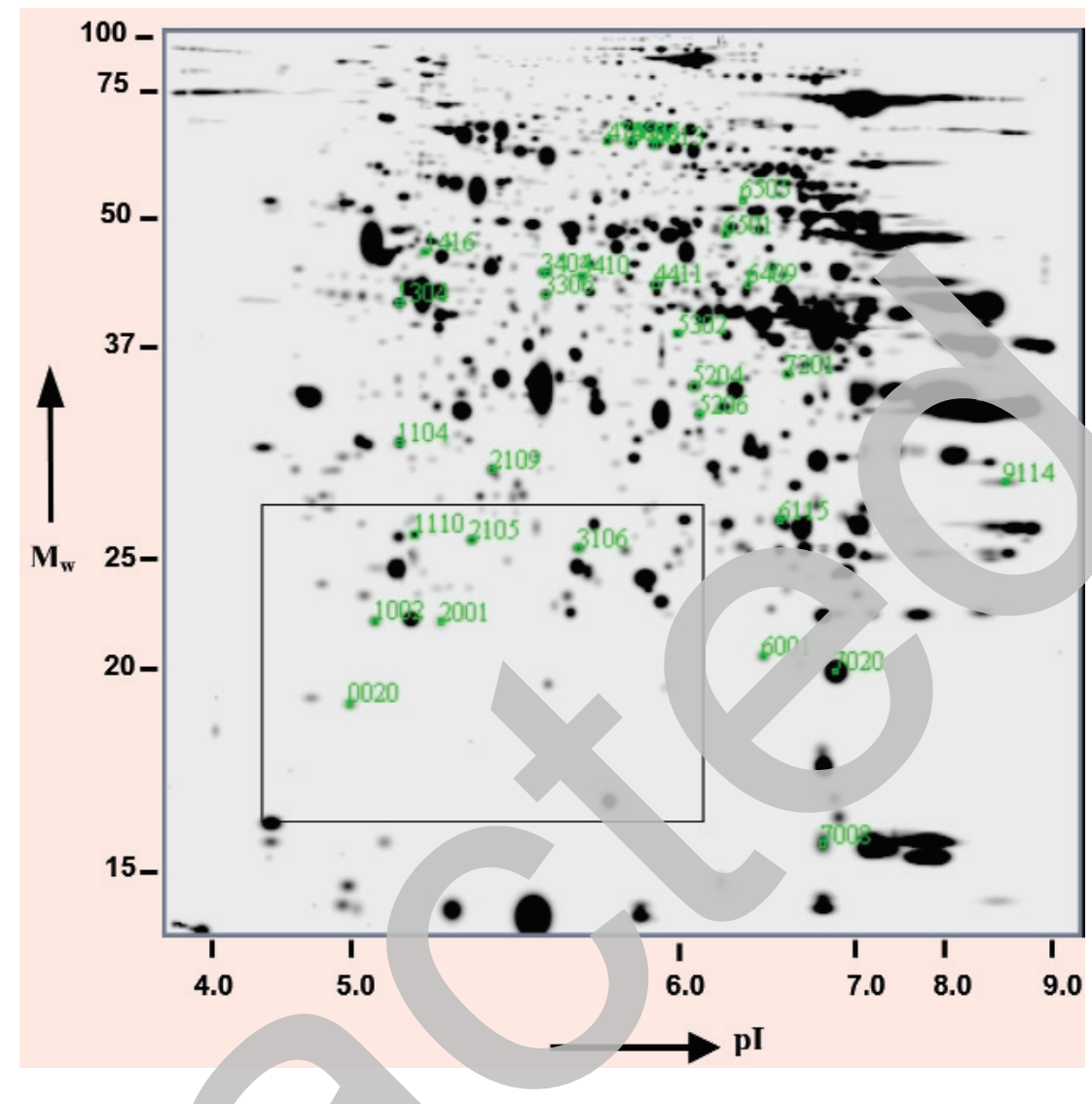

\section{Discussion}

To the best of our knowled ge this study shows for the first time the application differential display proteomics to study the molecular mechanisms involved in the cardioprotection by resveratrol. Proteomics is an emerging field that has e.g. the potential to rapidi uncover functional candidate protein from complex protein mixtures $[11-14,23-24]$ roteonics is an ideal approach by which elucidation of post-translational modifications associated with kinase activation is possible enabling one to evaluate on a global scale instead of a 14 small set of proteins. Herein we describe the use of such approach to identify redox-regulated and resveratrol-induced preconditioning associated proteins in the cytoplasmic subfractions isolated from cardiac homogenates. The reason of starting with this subfraction was to increase the proteome coverage by 2-DE [11-14]. The results of the present study demonstrate that proteomic profiling enables the identification of several resveratrol induced preconditioning-associated proteins.
Pharmacological preconditioning was already subject for a detailed proteomic investigation, though the aims of the study were different: 1) as the model was used isolated rabbit ventricular myocytes that were treated for $60 \mathrm{~min}$ at $37^{\circ} \mathrm{C}$ with $100 \mu \mathrm{M}$ adenosine [22] and 2) the myofilament-enriched subproteome was examined. Nevertheless, it is interesting to note that the differential proteomic analysis revealed a previously unsuspected in vivo posttranslational modification (phosphorylation) of MLC1. In the present study resveratrol downregulated cytoplasmic cardiac MLC kinase-2 after ischemia-reperfusion, which could be extrapolated to a reduced extent of phosphorylation of the MLCs.

Given the fact that resveratrol provides cardioprotection through preconditioning, we were particularly interested in the upregulated proteins known to be related to preconditioning. These proteins include MAPKK, peroxiredoxin-2, HSP27, $\alpha \mathrm{B}$ crystallin and phosphatidyl ethanolamine binding protein. Interestingly enough, some of these proteins are also redox-regulated. Evidence already exists in the literature indicating that MAP 


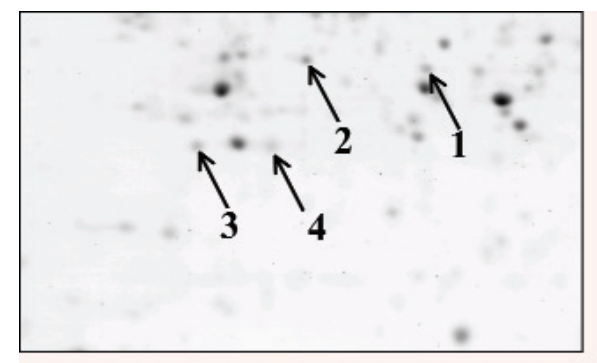

\section{Control}

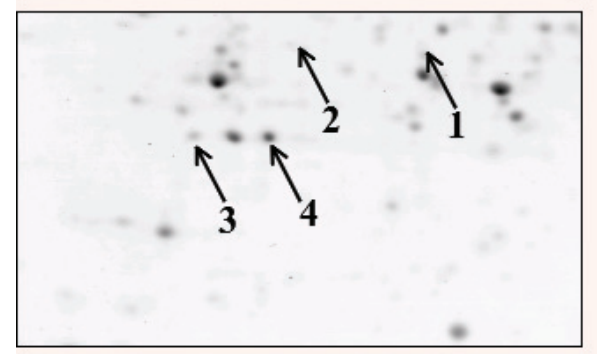

IR

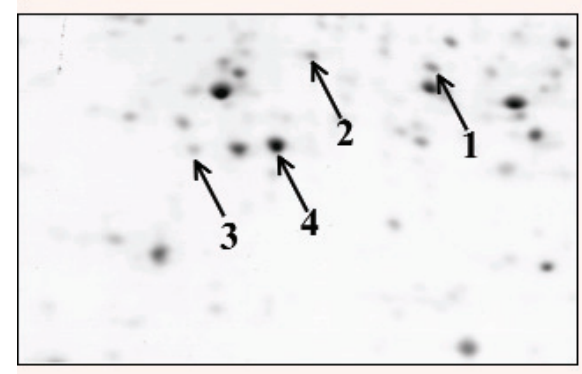

1 = HSP27 (3101) $3=$ peroxiredoxin-2 (23)

$2=$ HSP27 (2103) $4=$ PE binding protein (1005

kinase cascades play an ir portant role in the cardioprotective effects of resverato [25]. Resveratrol and related antioxidant component of wines and grapes, proanthocyanidins have been found to modulate $\mathrm{p} 38 \mathrm{MADK}, \mathrm{JNK}$ and ERK $1 / 2$ activities in the hear $[26,27]$. The same MAP kinases are also in olved in classical ischemic preconditioning [28]. ig shows the validation of the proteomic findings by Western blot analysis. However, it should be taken into account that on 2DE for each, HSP27 and $\alpha \mathrm{B}$ crystallin, two molecular forms were round to be differentially expressed. Table 1 snows that the apparent electrophoretic mobility $\left(\mathrm{M}_{\mathrm{wt}}\right.$ and $\left.\mathrm{pI}\right)$ of only one $\alpha \mathrm{B}$ crystalline species agrees well with its theoretical $\mathrm{M}_{\mathrm{wt}}$ and $\mathrm{I}$ values. On the other hand peroxiredoxin, which does not show a clear resveratrolinduced upregulation on differential 2-DE analysis, has the expected electrophoretic mobility according to the theoretical $\mathrm{Mw}$ and $\mathrm{pI}$ values. Therefore, its is likely that peroxiredoxin-2 is not in phosphorylated form. Nevertheless, Western
Fig. 4 Differential expression of four of the p. conditioning related proteins that were mostly found to be upregulated by resve ol treatment (compare also Table 1) Representative scetions o the real 2-DE gel images of the left ventricular cytoplasmic fraction from contol perfused and ische ia-reperfuse myocarum and ischemiareperiused plus resveratrol treated nyocardium. blot analysis confirms the previous findings and demonstrates that resveratrol modulates the activities of these MAP kinases and its downstream targets. HSP 27, the downstream target of p38MAPK and MAPKAP kinase 2 has been known to be phosphorylated in the preconditioned heart. Our results also show increased phosphorylation of $\alpha B$-crystallin, a close member of HSP 27.

PE-binding protein family consists of a number of 21-23 kDa basic proteins, some of which can act as suppressor of Raf-1 kinase activity and mitogenactivated protein kinase signaling via their ability to sequester and inactivate Raf-1 and MEK1 [29]. Both Raf-1 and MEK bind to the highly conserved PE-binding domain of the PE binding protein, which behaves as a competitive inhibitor of MEK phosphorylation. Recently, some member of the PE binding protein family was found to function as a survival-enhancing molecule, inhibiting TNF $\alpha$ induced apoptosis by interfering with Ras/Raf/MEK/ERK signaling, JNK activation and PE externalization. Thus, it appears that this protein 


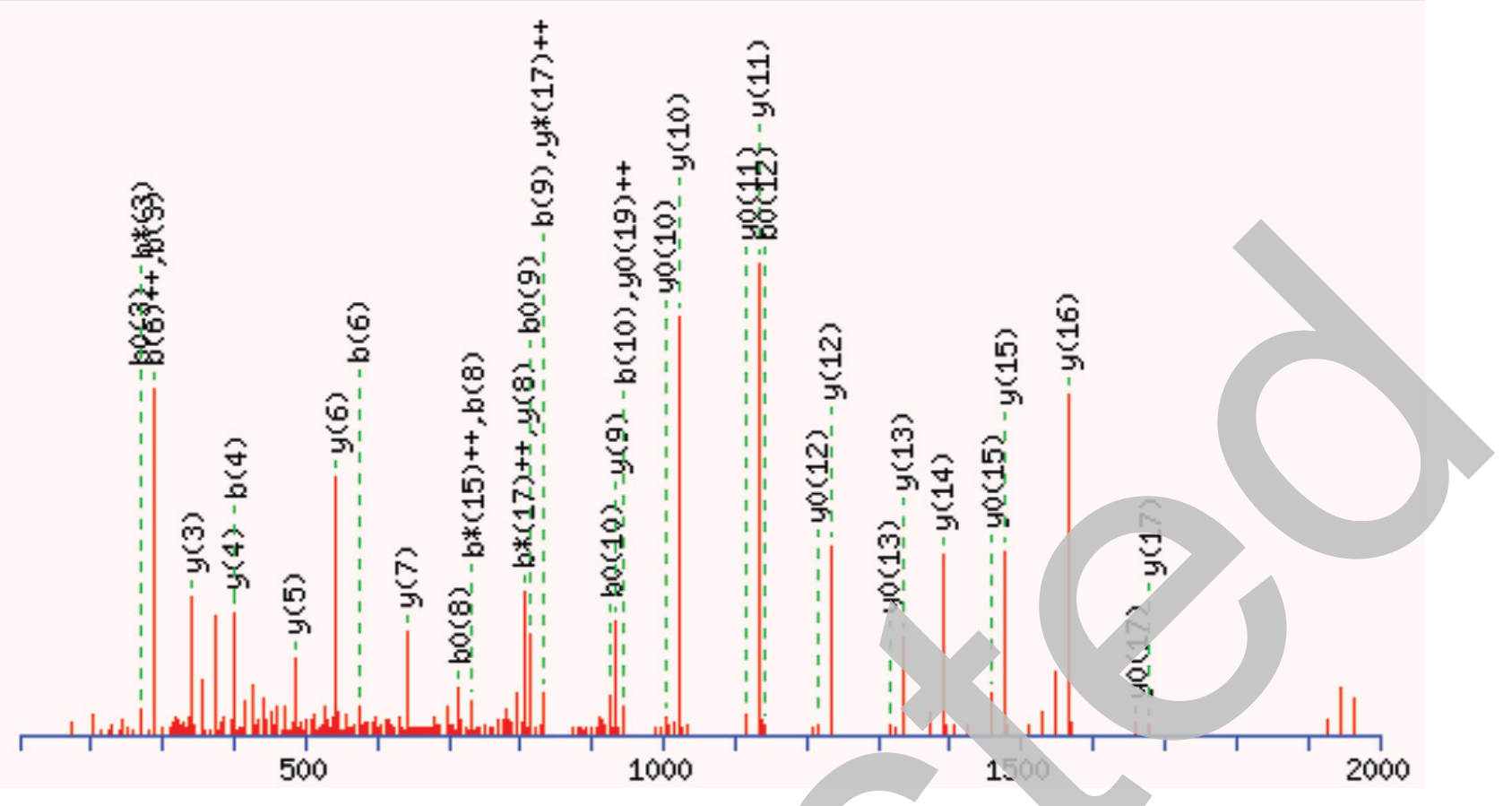

Fig. 5 Illlustrative example of the nano elektro spray tandem MS s ectrum of the frictented tryptic peptide with mono isotopic $\mathrm{M}_{\mathrm{w}}$ of 1962.9534 as obtained during the identification anal sis of the trypsin digested 2-DE spot containing PE lipid binding protein (upper panel). The fragmentation spectrum show the $\mathrm{m} / \mathrm{z}$ peak of the b-and y-ions, which denote fragmentations at the amide with charge retention on the $N$ or C-termin us of the tiypic peptide. The lower panel shows, in underlined and bold, the sequence of the matching typtic pe tides on which the overall identification (sequence coverage of $31 \%$, compare also Table 1) was based including in boid red he sequence derived from the MS/MS spectrum shown in the upper panel.

is also related to ischemic preconditioning. Our Western blot results indeed show activation of PE binding protein in the preconditioned myocardiun.

There is an additional salient feature in this study. The known propert o PKCe to form multi protein signaling complex to accomplis` signal transduc- tion in cardiac protection was efficiently exploited by Ping et al. [30, 31]. Numerous structural and signaling molecules that had previously escaped detection were identified. Most importantly, also metabolism related and transcription/translation related proteins were unmasked. In total 93 proteins.
Fig. 6 Representative

Western blot analysis of ISP2 7, $x$ B-crystallin, poroxire oxin 2, MAP kinase kinase and PE-binding protein. Induction of the expression of the proteins by resveratrol is shown under identical protein loading condition (not shown in the Figure) $(n=3$ per group).
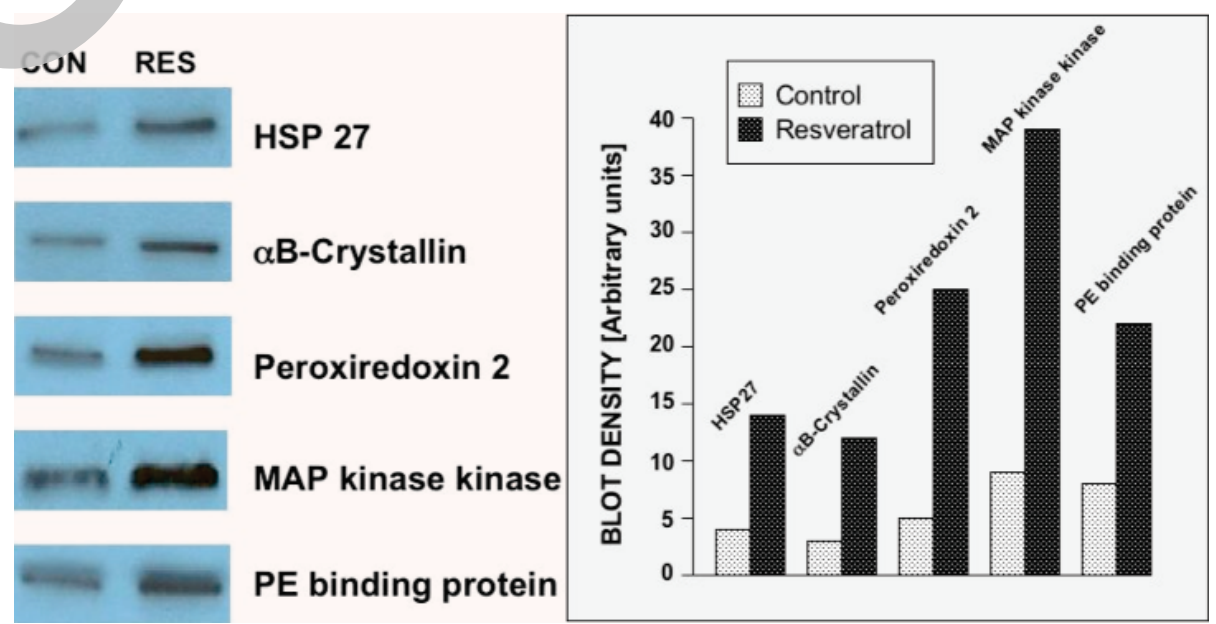
Conceptionally, this so-called functional proteomics approach enables an unbiased, yet focused, investigation of all participating molecules and provides a blueprint of the entire signaling network [32]

In conclusion, the results of the present study demonstrate that proteomic profiling enables the identification of several preconditioning-associated proteins (MAPKK, $\alpha \mathrm{B}$-crystallin, HSP27 and PE which reflect not only changes in their expression level but also isoforms, posttranslational modifications such as phosphorylation and regulating binding or activating partner proteins (e.g. cardiac MLC kinase 2).

\section{Acknowledgements}

This study was supported in part by NIH HL 34360 , HL22559, and HL33889.

\section{References}

1. Bradamante S, Piccinini F, Barenghi L, Bertelli AA, De Jonge R, Beemster P, De Jong JW. Does resveratrol induce pharmacological preconditioning? Int $J$ Tissue React. 2000; 2: 1-4.

2. Hung LM, Chen JK, Hong SS, Lee RS, Su MJ. Cardioprotective effect of resveratro a natural antioxidant derived from grapes. Cardiovasc Res. 2000; 47: 549-55.

3. Hattori R, Otani H, Maulik N, D. DK. Pharmacological preconditioning with resveratrol re of nitric oxide. Am J Physio Heart Circ Physiol. 2002; 282: H1988-95.

4. Kopp P. Resvera l, a phyt rogen found in red wine. A possible explanation for the con rum of the 'French paradox'? Eur J Endoc inol. 1998;138; 619-20.

Das DI, Maulik N. Resveratrol in cardioprotection: a therapeutic promise of alternative medicine. Mol Interv. 2006; 6: 36-47.

6. Imanura G, Bertelli AA, Bertelli A, Otani H, Maulik N Das DK. Pharmacological preconditioning with veratrol: an insight with iNOS knockout mice. $\mathrm{Am} \mathrm{J}$ siol Heart Circ Physiol. 2002;282: H1996-2003.

7. Das S, Alagappan VK, Bagchi D, Sharma HS, Maulik N, Das D K. Coordinated induction of iNOS-VEGF-KDReNOS af er resveratrol consumption: a potential mechanism for resveratrol preconditioning of the heart. Vascul Pharmacol. 2005; 42: 281-9.

8. Hung LM, Su MJ, Chen JK. Resveratrol protects myocardial ischemia-reperfusion injury through both NOdependent and NO-independent mechanisms. Free Radic Biol Med. 2004; 36: 774-81.
9. Das S, Tosaki A, Bagchi D, Maulik N, Das DK. Resveratrol-mediated activation of cAMP response element-binding protein through adenosine A3 receptor by Akt-dependent and -independent pathways. J Pharmacol Exp Ther. 2005; 314: 762-9.

10. Das S, Cordis GA, Maulik N, Das DK. Pharmacological preconditioning with resveratrol: role of CREB-dependent Bcl-2 signaling via adenosine $\mathrm{A} 3$ receptor activation. Am J Physiol Heart Circ Physiol. 2005; 288: H328-35.

11. Faber MJ, Agnetti G, Bezstarosti K, Lankhwizen IM, Dalinghaus M, Guarnieri C, Caldarera CM, Helbing

WA, Lamers JM. Recent developments in proteomics implications for the study of cardiac hypert hy and failure Cell Biochem Biophys. 2006; 44:

12. Faber MJ, Dalinghaus M, Lank'iuizen IM, Bezstarosti K, Dekker DH, Duncker D , Aelbing WA, Lamers JM. Proteomic changes in the pressure overloaded right ventricle afte 6 weeks in young rats: colrelations with the degree of hypertrophy Proteomics. 2005; 5: 2519-30.

13. McGregor E, Dunn MJ Proteomics of the heart: unraveling liseaso. Circ Res. 2006; 98, 309-21.

14. Van Eyk JE. Proteomics. unaveling the complexity of heart disease and striving to change cardiology. Curr Opin Mol Ther. 2001; 3: 546-53.

5. Engelman DT, W atanabe M, Engelman RM, Rousou JA, Kisin E, Kagan VE, Maulik N, Das DK. Cardiovasc 1995; 29: 133-140

S. to M, Cordis GA, Maulik N, Das DK. SAPKs regulatio of ischemic preconditioning. Am J Physiol Heart Circ Ph iol. 2000; 279: H901-7.

17. Maulik N, Sasaki H, Addya S, Das DK. Regulation of cardiomyocyte apoptosis by redox-sensitive transcription factors. FEBS Lett. 2000; 485: 7-12.

18. Wang X, Li N, Liu B, Sun H, Chen T, Li H, Qiu J, Zhang L, Wan T, Cao $\mathbf{X}$. A novel human phosphatidylethanolamine-binding protein resists tumor necrosis factor alpha-induced apoptosis by inhibiting mitogenactivated protein kinase pathway activation and phosphatidylethanolamine externalization. J Biol Chem. 2004; 279: 45855-64.

19. Das DK. Redox regulation of cardiomyocyte survival and death. Antioxid Redox Signal 2001;3: 23-37.

20. Ray PS, Martin JL, Swanson EA, Otani H, Dillmann WH, Das DK. Transgene overexpression of alphaB crystallin confers simultaneous protection against cardiomyocyte apoptosis and necrosis during myocardial ischemia and reperfusion. FASEB J. 2001; 15: 393-402.

21. Uchiyama T, Engelman RM, Maulik N, Das DK. Role of Akt signaling in mitochondrial survival pathway triggered by hypoxic preconditioning. Circulation. 2004; 109 : 3042-9.

22. Arrell DK, Neverova I, Fraser H, Marban E, Van Eyk JE. Proteomic analysis of pharmacologically preconditioned cardiomyocytes reveals novel phosphorylation of myosin light chain 1. Circ Res. 2001; 89: 480-7.

23. Arrell DK, Neverova I, Van Eyk JE. Cardiovascular proteomics: evolution and potential. Circ Res. 2001; 88: 763-73. 
24. Lam L, Lind J, Semsarian C. Application of proteomics in cardiovascular medicine. Int J Cardiol. 2006; 108: 12-9.

25. Das S, Tosaki A, Bagchi D, Maulik N, Das DK. Potentiation of a survival signal in the ischemic heart by resveratrol through p38 mitogen-activated protein kinase/mitogen- and stress-activated protein kinase 1/cAMP response element-binding protein signaling. $J$ Pharmacol Exp Ther. 2006; 317: 980-8.

26. Kutuk O, Poli G, Basaga H. Resveratrol protects against 4-hydroxynonenal-induced apoptosis by blocking JNK and c-JUN/AP-1 signaling. Toxicol Sci. 2006; 90: 120-32.

27. Maulik N, Watanabe M, Zu YL, Huang CK, Cordis GA, Schley JA, Das DK. Ischemic preconditioning triggers the activation of MAP kinases and MAPKAP kinase 2 in rat hearts. FEBS Lett. 1996; 396: 233-7.

28. Pataki T, Bak I, Kovacs P, Bagchi D, Das DK, Tosaki A. Grape seed proanthocyanidins improved cardiac recovery during reperfusion after ischemia in isolated rat hearts. $\mathrm{Am}$ J Clin Nutr. 2002; 75: 894-9.

29. Yeung K, Seitz T, Li S, Janosch P, McFerran B, Kaiser C, Fee F, Katsanakis KD, Rose DW, Mischak H, Sedivy JM, Kolch W. Suppression of Raf-1 kinase activity and MAP kinase signalling by RKIP. Nature 1999; 401: 173-7.

30. Ping P. Identification of novel signaling complexes by functional proteomics. Circ Res. 2003; 93: 595-603.

31. Vondriska TM, Ping P. Multiprotein signaling complexes and regulation of cardiac phenotyp. I Mol Cell Cardiol. 2003; 35: 1027-33.

32. Edmondson RD, Vondriska TM, Biederman K. Zhang J, Jones RC, Zheng Y, Allen DL, Xiu JX, Cardwell EM, Pisano MR, Pino P. Proten kinase $C$ epsilon signaling complexes include metabolism- and
transcription/translation- 1 elated proteins. complimentary

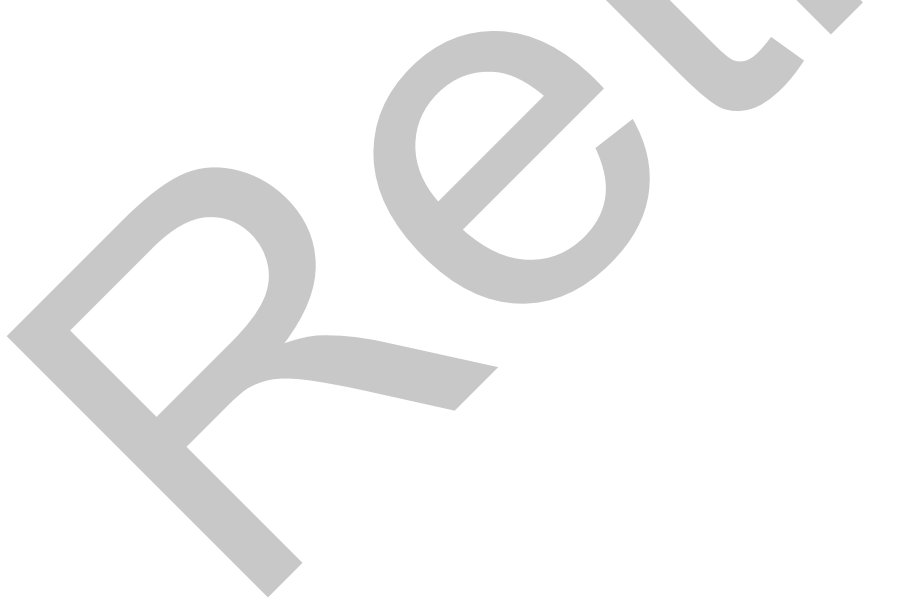

